\title{
PENYELIDIKAN KARAKTERISTIK MEKANIK TARIK PADUAN ALUMINIUM MAGNESIUM (AL-MG) DENGAN METODE PENGECORAN KONVENSIONAL
}

\author{
Fadly A. Kurniawan Nst $^{1}$ Ikhwansyah Isranuri $^{2}$ \\ 1.Staff Pengajar Jurusan Teknik Mesin, Sekolah Tinggi Teknik Harapan, Medan \\ 2. Staff Pengajar Departemen Teknik Mesin, Fakultas Teknik, USU Medan
}

\begin{abstract}
Making the Al-Mg alloy successfully done using conventional metal casting method. The composition of the investigated alloy is $98 \%-2 \%, 96 \%-4 \%$, and $94 \%-6 \%$ (Aluminum - Magnesium). From the tensile test results for the third composition of the alloy to alloy with the composition of the Al-Mg $98 \%-2 \%$ obtained modulus of elasticity of $4.44 \mathrm{GPa}$. For alloys with compositions of $\mathrm{Al}-\mathrm{Mg} 96 \%-4 \%$, obtained value of the modulus of elasticity of $4.46 \mathrm{GPa}$. As for Al-Mg alloy $94 \%-6 \%$, obtained value of modulus of elasticity of 3.56 $\mathrm{GPa}$. From the tensile test results above, it was found that the best modulus of elasticity obtained for both compositions, is $96 \%-4 \%$.
\end{abstract}

Keywords: Al-Mg Alloys, Tensile Strength, Modulus of Elasticity.

\begin{abstract}
Abstrak
Pembuatan paduan Al-Mg dilakukan dengan menggunakan metode pengecoran. Komposisi paduan yang akan diteliti adalah 98\% - 2\%, 96\% - 4\%, dan 94\% - 6\% (perbandingan Aluminium - Magnesium). Dari hasil pengujian tarik didapatkan modulus elastisitas paduan Al-Mg dengan komposisi 98\%-2\% sebesar $4.44 \mathrm{GPa}$. Untuk paduan 96\%-4\% sebesar $4.46 \mathrm{GPa}$, dan untuk paduan 94\%-6\% sebesar $3.56 \mathrm{GPa}$. Hasil terbaik didapatkan dari komposisi $96 \%-4 \%$ yaitu sebesar 4,46 GPa.
\end{abstract}

Kata Kunci: Al-Mg Alloy, Kekuatan Tarik, Modulus Elastisitas.

\section{Pendahuluan}

\subsection{Latar Belakang Masalah}

Indonesia merupakan negara kepulauan yang luas seluruhnya $5.193 .250 \mathrm{~km}^{2}$, dan hampir dua pertiga wilayah Indonesia merupakan wilayah perairan dengan luas mencapai $3.287 .010 \mathrm{~km}^{2}$. Kondisi ini tentunya membutuhkan pengelolaan, pemeliharaan dan pengamanan sehingga sumber daya yang dimiliki Indonesia tidak berpindah ke negara lain. Berdasarkan fakta tersebut, sangat perlu untuk mengembangkan sebuah pesawat udara tanpa awak (Unmanned Aerial Vehicle atau disingkat UAV) yang bertujuan sebagai sarana pendukung pemantauan keadaan wilayah Indonesia untuk mendapatkan data yang lebih detail, real time, cepat, dan murah. Pesawat Udara tanpa awak merupakan sebuah wahana terbang yang dikendalikan dari jarak jauh untuk melakukan misi tertentu.

Aluminium paduan telah lama digunakan pada aplikasi-aplikasi tertentu karena memiliki kombinasi sifat mekanis yang antara lain kekuatan yang tinggi, densitas yang rendah, durabilitas yang baik, kemampuan ketermesinan yang baik, dan juga biaya yang cukup kompetitif (Girisha, H.N, 2012).
Paduan Aluminiun Magnesium (Al-Mg) sebagai material akustik yg memiliki kemampuan absorpsi suara akan diuji dalam penelitian ini. Ada beberapa perbedaan sifat yang mendasar dari Aluminium (Al) dan Magnesium (Mg). Aluminium memiliki karakteristik ductile yang baik, ketahanan terhadap korosi, kemampuan cor yang baik, dan harga yang lebih murah. Sedangkan Magnesium memiliki sifat damping yang baik, densitas yang rendah sehingga lebih ringan, tetapi harga yang lebih mahal (TengShih, 2010). Dengan penggabungan kedua jenis metal diatas, diharapkan didapatkan sebuah paduan yang memiliki karakteristik ductile yang baik, tahan terhadap korosi, ringan, dan memiliki sifat serap bunyi yang baik. Melalui penelitian akan dikembangkan sebuah prototipe propeller rendah bising pada pesawat tanpa awak dengan menggunakan material paduan Aluminium Magnesium (Al-Mg).

\subsection{Tujuan Penelitian}

Penelitian ini bertujuan untuk mendapatkan nilai kekuatan tarik dari paduan $\mathrm{Al}-\mathrm{Mg}$ pada beberapa komposisi yaitu 98\%-2\%, 96\%-4\%, dan 94\%-6\% (\% Al: \% Mg). 


\subsection{Paduan Aluminium - Magnesium (Al-Mg)}

Aluminium banyak dipakai dengan paduan unsur lain sebab tidak kehilangan sifat ringan dan sifat-sifat mekanisnya, serta mampu cornya diperbaiki dengan menambah unsur-unsur lain. Unsur-unsur paduan yang ditambahkan pada aluminium selain dapat menambah kekuatan mekaniknya juga dapat memberikan sifat-sifat baik lainnya seperti ketahanan korosi dan ketahanan aus. Keberadaan magnesium hingga $15,35 \%$ dapat menurunkan titik lebur logam paduan yang cukup drastis, dari $660^{\circ} \mathrm{C}$ hingga $450^{\circ} \mathrm{C}$. Namun, hal ini tidak menjadikan aluminium paduan dapat ditempa menggunakan panas dengan mudah karena korosi akan terjadi pada suhu di atas $60^{\circ} \mathrm{C}$. Keberadaan magnesium juga menjadikan logam paduan dapat bekerja dengan baik pada temperatur yang sangat rendah, di mana kebanyakan logam akan mengalami failure pada temperatur tersebut.

Aluminium alloy yang terdiri dari paduan utama Si dan Mg pada perbandingan tertentu akan terbentuk magnesium silica, yang akan membuat aluminium jenis ini mampu untuk dilakukan heat treatment, ketangguhan akan berkurang jika dibandingkan dengan paduan Aluminium $\mathrm{Cu}$ dan $\mathrm{Zn}$. Silikon memiliki sifat yang getas dan dapat dengan mudah mengalami crack, seperti fatik terjadi didalam Alloy Al-Si terutama dengan pengintian dan pertumbuhan microcrack yang terdapat pada sekeliling fasa magnesium atau di dalam matriks aluminium (Ye.H, 2002).

\section{Metode dan Peralatan}

\subsection{Pembuatan Spesimen Uji}

\subsubsection{Bahan}

Bahan yang digunakan dalam penelitian ini adalah ingot Aluminium (Al) dan Magnesium (Mg) yang di lebur untuk memperoleh paduan material yang baru yaitu Aluminium-Magnesium (Al-Mg) yang akan digunakan sebagai material rendah bising pada propeller.

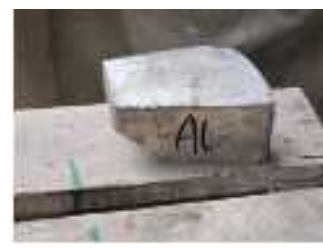

A

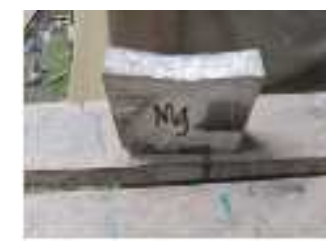

b
Gambar 1. (a) Ingot Aluminium (b)Ingot Magnesium

\subsubsection{Peralatan Pembuatan Spesimen}

Penelitian ini diawali dengan melakukan peleburan ingot Aluminium dan Magnesium. Peleburan dilakukan di industri peleburan Aluminium. Setelah di dapatkan material hasil peleburan, kemudian dilakukan pengujian material di laboratorium.

Peralatan yang di gunakan dalam proses peleburan Aluminium dan Magnesium yang akan digunakan sebagai spesimen adalah:

1. Dapur Lebur

Dapur lebur digunakan sebagai tempat meleburkan material. Bahan bakar yang digunakan pada dapur lebur adalah kayu yang sebelumnya sudah dikeringkan. Kapasitas dapur lebur yang digunakan pada penelitian ini adalah 10 liter (10 $\left.\mathrm{dm}^{3}\right)$.

\section{Blower}

Blower digunakan untuk menjaga temperatur peleburan yang dihasilkan dari panas pembakaran pada kayu bakar. Tanpa alat ini, maka panas yang dihasilkan dari proses pembakaran tidak terdistribusi dengan baik dan panas yang dihasilkan tidak maksimal.

\section{Cetakan Pasir}

Cetakan pasir dibuat dengan membentuk pasir kemudian dipadatkan agar hasil cetakan tidak berubah bentuk. Pasir yang digunakan adalah pasir alam atau pasir buatan yang mengandung tanah lempeng. Pasir ini dicampur pengikat khusus seperti air, bentonit, semen, resin ferol, minyak pengering. Bahan tersebut akan memperkuat dan mempermudah operasi pembuatan cetakan.

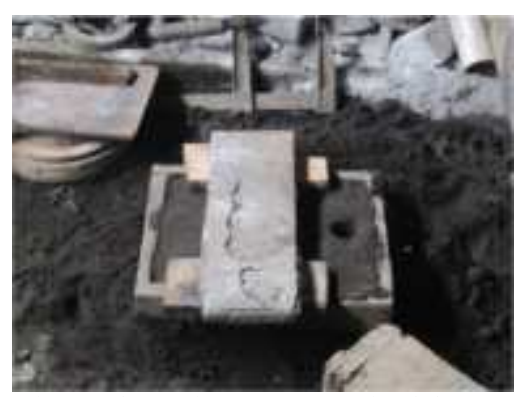

Gambar 2. Cetakan Pasir untuk pengecoran AluminiumMagnesium (Al-Mg)

Proses pembuatan spesimen uji pada penelitian ini adalah sebagai berikut:

1. Ingot Aluminium dan Magnesium di potong dengan menggunakan mesin dengan dimensi yang kecil. Pemotongan ini dilakukan untuk mempermudah menghitung perbandingan paduan $\mathrm{Al}$ dan $\mathrm{Mg}$ pada saat proses pengecoran.

2. Spesimen di timbang sesuai dengan jumlah $\%$ paduan yang akan dibuat.

3. Dapur lebur mulai dipanaskan.

4. Ingot Aluminium di masukkan ke dalam tungku peleburan, dan dileburkan hingga suhu $800{ }^{\circ} \mathrm{C}$.

5. Setelah Aluminium Mulai mencair, Magnesium dimasukkan ke dalam tungku peleburan, dimana 
sebelumnya Magnesium mengalami proses pemanasan awal.

6. Setelah kedua material mencair di dalam tungku peleburan, cairan material tersebut di berikan flux yang berguna untuk mengangkat kotoran/kerak pada cairan Aluminium Magnesium.

7. Proses selanjutnya adalah pencetakan dengan menggunakan cetakan pasir dan cetakan besi.

8. Paduan Al-Mg didinginkan secara alami.

\subsection{Pengujian Tarik}

Pengujian tarik pada penelitian ini berdasarkan standar ASTM D638, dengan ukuran spesimen diperlihatkan pada gambar 3 .

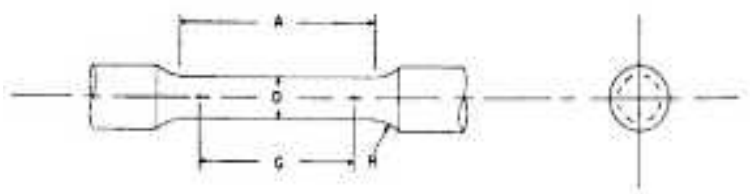

Gambar 3. Bentuk spesimen uji tarik standar ASTM E8 untuk uji metal

\begin{tabular}{|c|c|c|c|c|c|}
\hline \multicolumn{6}{|c|}{ Drews } \\
\hline & 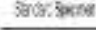 & & 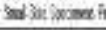 & ton 0 ind & \\
\hline & $\overline{1}$ & $\pi$ & in & I & 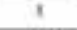 \\
\hline Hodtionat & cai & of & 3 & Wi & 11) \\
\hline 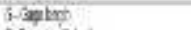 & III) & $19+1 B$ & 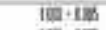 & 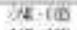 & Iatcin \\
\hline Horee in? & $150=23$ & $100 \pm 18$ & $M i t \sigma_{0}$ & $2 \pi: 600$ & $(D)=1 \mathrm{Mx}$ \\
\hline Afoldudit: = & 4 & $y$ & $7_{i}$ & n & $\mathrm{za}$ \\
\hline  & 8 & 8 & 1. & $\mathrm{i}$ & $k$ \\
\hline
\end{tabular}

Gambar 4. Standar Ukuran uji tarik standar ASTM E8 untuk uji metal

\section{Hasil dan Pembahasan}

\subsection{Hasil Uji Tarik}

Untuk mendapatkan perilaku mekanik paduan Al$\mathrm{Mg}$, dilakukan pengujian tarik untuk mendapatkan tegangan, regangan, dan modulus elastisitas material paduan Al-Mg. Material paduan $\mathrm{Al}-\mathrm{Mg}$ pada penelitian ini akan menggunakan 3 (tiga) komposisi, yaitu:
1. Kompisisi 1. Degan komposisi Al-Mg $(98 \%-2 \%)$
2. Komposisi 2. Dengan komposisi Al-Mg $(96 \%-4 \%)$
3. Komposisi 3. Dengan komposisi Al-Mg $(94 \%-6 \%)$

Tabel 1. Nilai Modulus Elastisitas

\begin{tabular}{|c|c|c|c|c|c|}
\hline $\begin{array}{c}\text { Komposi } \\
\text { si }\end{array}$ & \multicolumn{2}{|c|}{$\begin{array}{c}\text { Spesimen } \\
\sigma(\mathrm{MPa})\end{array}$} & $\begin{array}{c}\mathrm{e} \\
(\%)\end{array}$ & $\begin{array}{c}\mathrm{E} \\
(\mathrm{MPa})\end{array}$ & $\begin{array}{c}\mathrm{E} \\
(\mathrm{Mean})\end{array}$ \\
\hline \multirow{2}{*}{$\mathrm{Al} 98 \%$} & $1 \mathrm{a}$ & 176,24 & 2,57 & 6846,47 & \\
\cline { 2 - 5 } $\mathrm{Mg} 2 \%$ & $1 \mathrm{~b}$ & 154,45 & 4,23 & 3648,08 & \multirow{2}{*}{4443,61} \\
\cline { 2 - 5 } & $1 \mathrm{c}$ & 165,83 & 5,85 & 2836,28 & \\
\hline $\mathrm{Al} 96 \%$ & $2 \mathrm{a}$ & 160,76 & 2,36 & 6818,88 & \\
\cline { 2 - 5 } $\mathrm{Mg} 4 \%$ & $2 \mathrm{~b}$ & 184,67 & 5,76 & 3205,44 & \multirow{2}{*}{4646,04} \\
\hline
\end{tabular}

\begin{tabular}{|l|l|l|l|l|l|}
\hline & $2 \mathrm{c}$ & 131,00 & 3,35 & 3913,80 & \\
\hline \multirow{3}{*}{$\mathrm{Al} 94 \%$} & $3 \mathrm{a}$ & 110,32 & 3,41 & 3238,37 & \\
\cline { 2 - 5 } $\operatorname{Mg} 6 \%$ & $3 \mathrm{~b}$ & 128,97 & 3,94 & 3275,78 & \multirow{3}{*}{3564,09} \\
\cline { 2 - 6 } & $3 \mathrm{c}$ & 110,62 & 2,65 & 4178,11 & \\
\hline
\end{tabular}

Grafik nilai modulus elastisitas rata-rata dapat dilihat pada Gambar 5 dibawah ini.

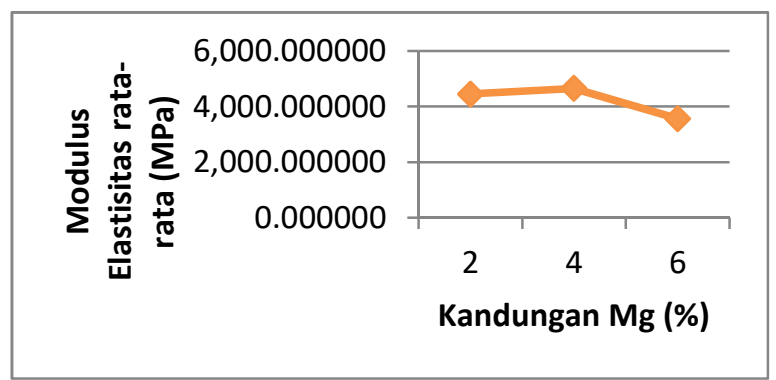

Gambar 5. Grafik nilai modulus elastisitas rata-rata untuk setiap komposisi paduan $\mathrm{Al}-\mathrm{Mg}$

Gambar 5 memperlihatkan bahwa semakin besar penambahan unsur Magnesium di dalam Aluminium, maka modulus elastisitas yang terjadi akan semakin kecil. Terjadi kenaikan nilai modulus elastisitas pada variasi $\mathrm{Al} \mathrm{96 \%} \mathrm{-} \mathrm{Mg} \mathrm{4 \% .} \mathrm{Ini} \mathrm{menunjukkan} \mathrm{bahwa}$ penambahan persen $\mathrm{Mg}$ dapat mengurangi tingkat keliatan paduan $\mathrm{Al}-\mathrm{Mg}$.

\section{Kesimpulan}

1. Metode pembuatan paduan Aluminium Magnesium (Al-Mg)

Pembuatan paduan Al-Mg berhasil dilakukan dengan baik menggunakan metode pengecoran logam konvensional. Komposisi paduan yang diteliti adalah 98\%-2\%, 96\%-4\%, dan 94\%-6\% (perbandingan Aluminium-Magnesium). Pada proses pembuatan paduan $\mathrm{Al}-\mathrm{Mg}$, pertama yang dilebur ingot Aluminium. Setelah mencapai suhu $650^{\circ} \mathrm{C}$, ingot Magnesium dimasukkan ke tungku lebur yang didalamnya sudah terdapat Aluminium. Kemudian paduan dibiarkan didalam tungku coran sampai suhu $800^{\circ} \mathrm{C}$. selama menunggu sampai pada suhu optimal, paduan yang berada didalam tungku perlu dilakukan beberapa kali pengadukan untuk mendapatkan paduan yang tercampur sempurna. Setelah paduan menjadi campuran yang homogen, paduan $\mathrm{Al}-\mathrm{Mg}$ cair ditungkan ke cetakan.

\section{Karakteristik Mekanik terhadap Uji Tarik}

Dari hasil pengujian tarik untuk ketiga komposisi paduan,didapatkan nilai modulus elastisitas sebagai berikut:Untuk paduan dengan komposisi Al-Mg 98\%-2\% didapatkan nilai modulus elastisitas sebesar 4443, $613 \mathrm{MPa}$. Untuk paduan dengan komposisi AlMg 96\%-4\%, didapatkan nilai modulus elastisitas sebesar 4466,039 Mpa. Sedangkan untuk paduan AlMg 94\%-6\%, didapatkan nilai Modulus elastisitas 
sebesar 3564,086 MPa. Dari hasil pengujian tarik diatas, didapatkan modulus elastisat yang terbaik didapat untuk komposisi kedua, yaitu 96\%-4\%.

\section{Daftar Pustaka}

[1] Anderson Jr dan Jhon D. Fundamental of Aerodyamics. Boston : Mc.Graw-Hill. 1999.

[2] Girisha, H.N dan K.V. Sharma. Effect of Magnesium on Strength and Microstructure of Aluminium Copper Magnesium Alloy, International Journal of Scientific \& Engineering Research, volume 3, Issue 2, February 2012.

[3] Teng-Shih, SHIH, Jyun-Bo, dan Pai-Sheng WEI. Thermally-Formed Oxide on Magnesium and Magnesium Alloys. National Central University, Taiwan.

[4] Toros Serkan, Fahrettin Ozturk, dan Ilyas Kacar. Review Warm Forming of Aluminium Magnesium Alloys. Elsevier. 2008. 